\title{
CÓRREGO BARREIRO - CONFIGURAÇÃo PAISAGÍSTICA E MODELAGEM HIDRÁULICA: UMA EXPERIÊNCIA MULTIDISCIPLINAR
}

\author{
STREAM BARREIRO - LANDSCAPE CONFIGURATION AND HYDRAULIC \\ MODELING: A MILTIDISCIPLINARY EXPERIENCE
}

Saide Kahtouni \& Luiz Fernando Orsini de Lima Yazaki

\begin{abstract}
- Arquiteta, urbanista e paisagista. Mestre e Doutora pela FAUUSP. Especialista em Gestão e tecnologias ambientais pela Escola Politécnica da USP. Autora do livro Cidade das águas. Autora principal do projeto Córrego do Barreiro e coordenação geral. Diretora técnica da LPK Avaliações técnicas, projetos e consultoria ambiental, com sede em São Paulo- capital, desde 1994. Contato: kahtouni@uol.com.br
\end{abstract}

\begin{abstract}
- Engenheiro civil, pós-graduado em saneamento e drenagem urbana pela Escola Politécnica da USP. Atua há mais de 30 anos nas áreas de saneamento, drenagem urbana e gestão de recursos hídricos. Foi coordenador técnico e científico da Cooperação Internacional Brasil-Itália em Saneamento Ambiental. Atualmente é líder de projetos da Fundação Centro Tecnológico de Hidráulica e consultor independente. Consultor para os estudos hidrológicos e cálculos hidráulicos no projeto em questão.
\end{abstract}

RESUMO: O presente estudo, realizado por equipe multidisciplinar, trata dos melhoramentos necessários na várzea do córrego Barreiro e medidas para amenização dos problemas de erosão e assoreamento constatados no curso d'água, num trecho de aproximadamente 300 metros, situado dentro da propriedade do Campus Universitário UNIP em Alphaville, Santana do Parnaíba, região metropolitana de São Paulo, que ali funciona há mais de duas décadas. Consideramos como premissa privilegiar as possibilidades de retenção no trecho e à montante dele, apenas corrigindo o talude de uma das margens e tratando paisagisticamente todo o conjunto, o das águas, e o de áreas inundáveis e terrenos, verificando possibilidades de dissipação dos fluxos de águas de chuva na contribuição final do trecho visando a acomodação adequada e harmoniosa de intervenções hidráulicas, implementação de vegetação nativa e contenções necessárias. Neste projeto hidráulico, a arquitetura paisagística e a modelagem hidráulica dialogaram e caminharam juntas, partindo da configuração desejada. 
ABSTRACT - This study, conducted by multidisciplinary team, proposed the improvements required in the floodplain of the Barreiro creek to mitigate erosion, siltation and flooding in a 300 meters stretch, located on the property of UNIP Campus in Alphaville, Santana do Parnaiba, São Paulo Metropolitan Region. The premise of the project was to control stormwater level using cheap solutions, avoiding heavy structural interventions and preserving the better as possible the natural landscape of the floodplain. The solution was just banks slope adjustments, floodplain reconfiguration, native vegetation recovery and a restriction at the end of the stretch to reduce downstream discharges. To achieve the ideal design the work was developed in intense dialogue among landscape architecture, geotechnical engineering and hydrology-hydraulics modeling. The result was an efficient storm water control device in a harmonious landscape just in front of UNIP Campus.

PALAVRAS-CHAVE: Planejamento de paisagem e hidrologia, conservação de recursos hídricos, infra-estrutura verde.

KEYWORDS: Planning and landscape hydrology, water conservation, green infrastructure. 


\section{INTRODUÇÃO}

Este artigo apresenta os resultados dos estudos paisagísticos associados a estudos hidrológicos e hidráulicos elaborados para o trecho do Córrego do Barreiro situado na área da Universidade Paulista - UNIP em Alphaville, Santana de Parnaíba, SP. Os objetivos deste trabalho, realizado em 2008, foram:

. Desenvolvimento do projeto de readequação e revitalização do Córrego do Barreiro no trecho do terreno da UNIP; fundamentar o processo de obtenção de outorga e licenciamento ambiental para melhoramentos no trecho, considerando:

- Intervenções no leito do córrego que incluem sua adequação às vazões de cheias, desassoreamento e obras de proteção das margens contra erosão;

- Intervenções para a recuperação e revitalização da área de preservação permanente;

- A regularização da outorga para travessia de pedestres existente sobre o córrego;

A obtenção de outorga de uma segunda travessia de pedestres a ser construída. Os estudos realizados consistiram na determinação dos hidrogramas de projeto, para diversos períodos de retorno, e das respectivas linhas de água para a situação atual e simulações partindo do desenho do projeto, gerado a partir de um novo traçado e configuração discutido em conjunto a partir do "master plan" ou desenho de concepção elaborado pela arquiteta paisagista e coordenadora da equipe multidisciplinar que envolveu geógrafo, engenheiros civis, hidráulicos e geotécnico. 


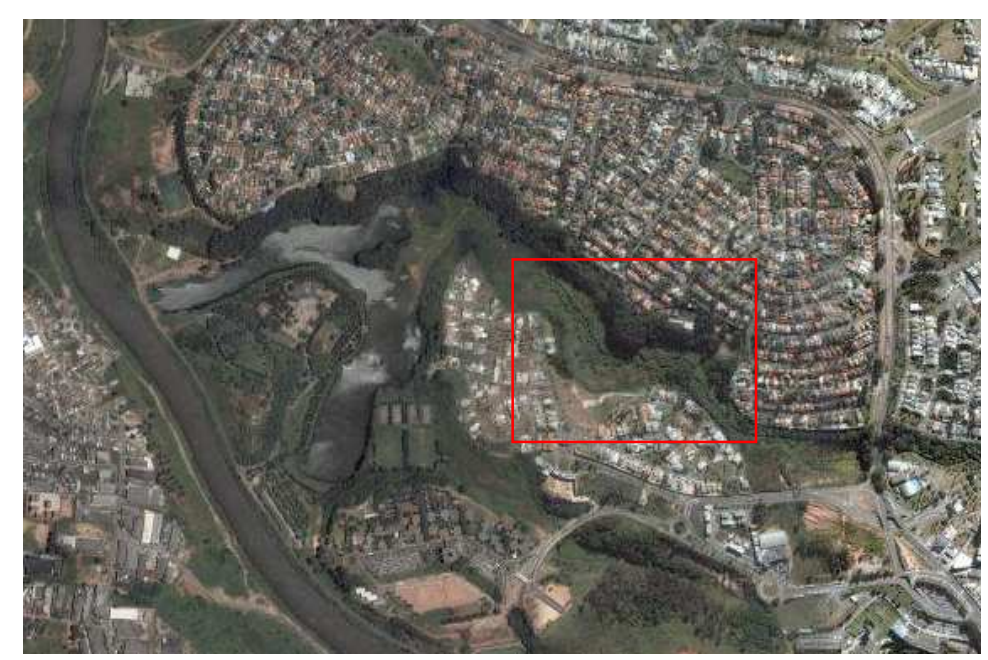

FIGURA 1 - local das intervenções

A proposta elaborada considerou a importância de sistemas de drenagem leves, associados às possibilidades de criação paisagística de permeabilidades máximas e de retenção em trechos situados a montante da área de intervenção do córrego. A utilização paisagística de colchões de rachão associados ao "rip-rap" (em amarelo) nas áreas de caminhamento de águas superficiais e indicação de retaludamento para inclinações mais leves e variáveis com inserção de revestimentos naturalísticos das margens inspirou-se nos trabalhos realizados na Itália, com destaque para RIZZO (2007). 


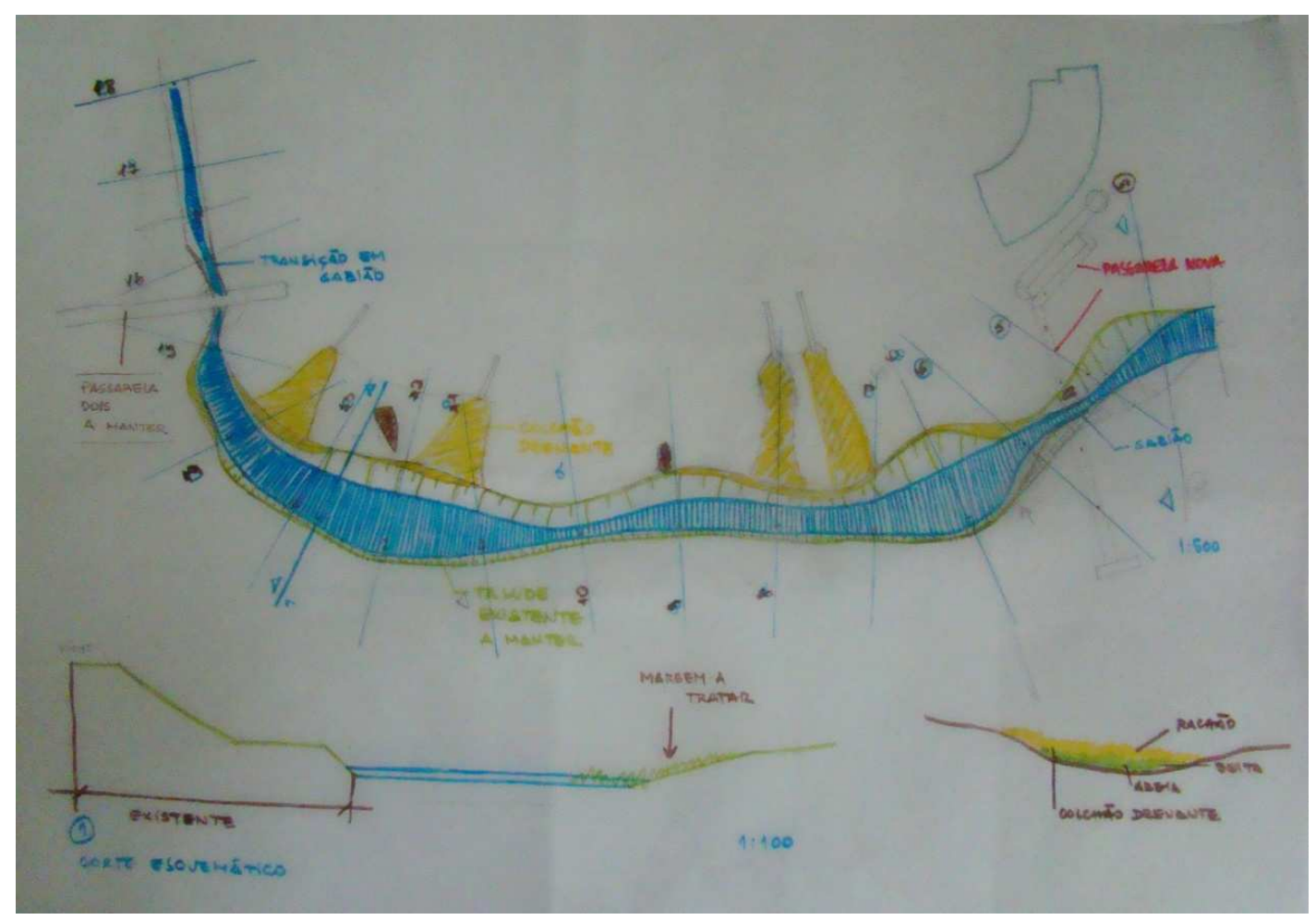

FIGURA 2 - Croquis de estudo - MASTER PLAN/ ARQUITETURA PAISAGÍSTICA- águas

Para os estudos hidrológicos buscou-se a determinação dos parâmetros de cálculo dos hidrogramas afluentes ao córrego a partir de uma caracterização detalhada da bacia do Barreiro utilizando-se técnicas de geoprocessamento que possibilitaram reduzir a subjetividade inerente a estudos desse tipo. As linhas de água foram definidas pelas envoltórias dos níveis máximos simulados no movimento variado, com o uso de sistema computacional de simulações hidrodinâmicas em canais associadas às secções de projeto geradas pela configuração paisagística projetada. 


\section{A BACIA}

A bacia do córrego do Barreiro está integralmente localizada no município de Santana de Parnaíba, zona oeste da RMSP. Pertence à unidade hidrográfica 6.6.9 - Córrego Garcia - situada na sub-região Pinheiros-Pirapora da Região Hidrográfica 6 - Bacia do Alto Tietê -, conforme designações do Plano da Bacia Hidrográfica do Alto Tietê (FUSP, 2007) ${ }^{\mathbf{1}}$. O córrego do Barreiro é afluente da margem direita do córrego do Garcia que, por sua vez, é afluente da margem direita do rio Tietê. Na seção da passarela de jusante da UNIP, a bacia hidrográfica do córrego do Barreiro possui uma área de $4,14 \mathrm{~km}^{2}$. A extensão total do córrego, que é afluente da margem direita do rio Tietê, é de cerca de 4 km. A figura 3 mostra a situação do córrego do Barreiro na Bacia Hidrográfica do Alto Tietê.

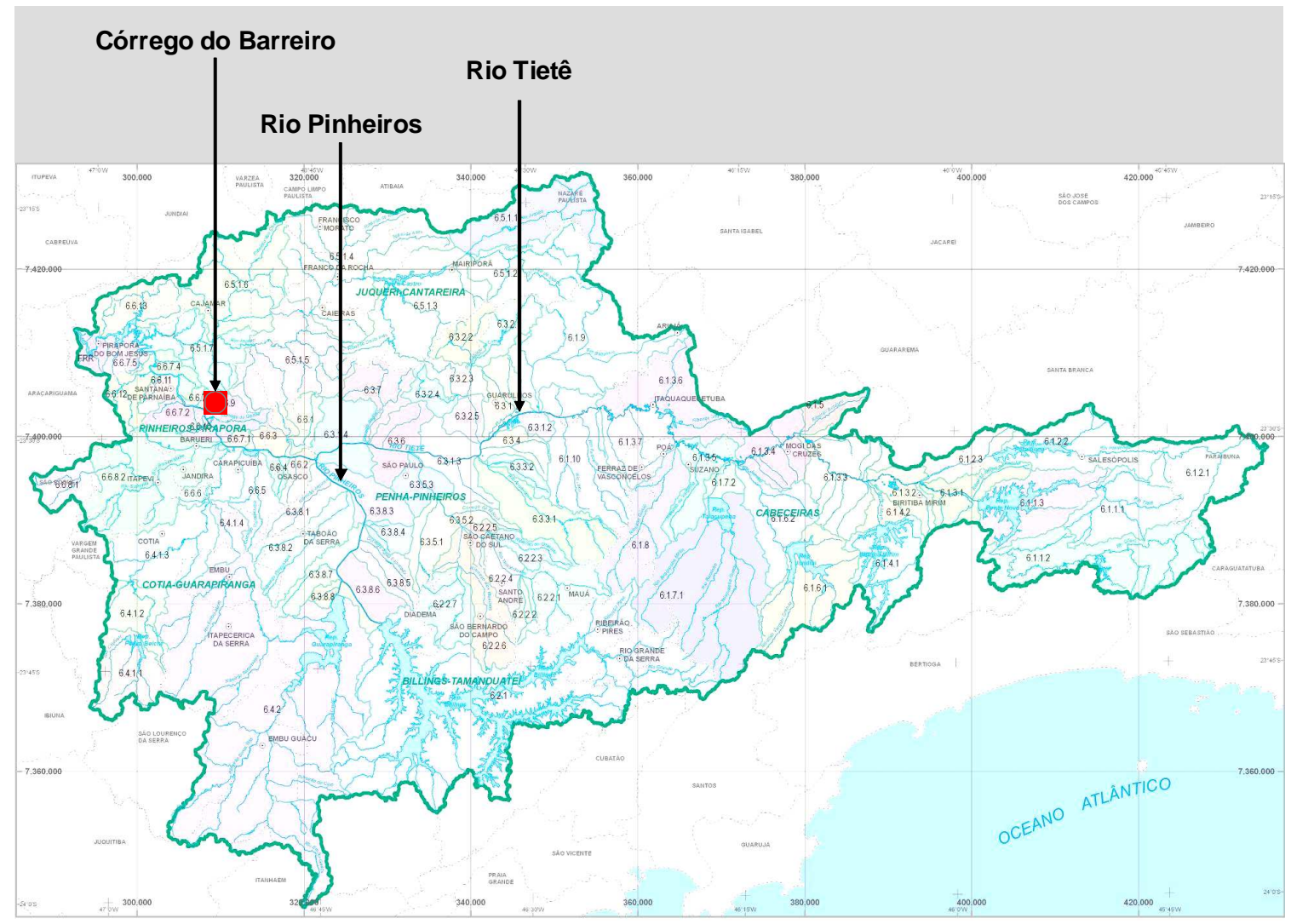

FIGURA 3 - LOCALIZAÇÃO DO CÓRREGO DO BARREIRO NA BACIA DO ALTO TIETÊ 


\section{ESTUDOS HIDROLÓGICOS}

Os hidrogramas de projeto das vazões afluentes ao córrego do Barreiro foram calculados por método consagrado de transformação chuva-vazão, já que não existe medição direta de vazões no local.

A metodologia utilizada para a determinação dos hidrogramas é a proposta pelo Soil Conservation Service - SCS, que vem sendo largamente empregada no Brasil, notadamente em São Paulo. Para o desenvolvimento das simulações hidrológicas foi utilizado como ferramenta o sistema CAbc desenvolvido pela Fundação Centro Tecnológico de Hidráulica - FCTH, para o cálculo de vazões em bacias complexas.

Por ser de uso corrente, amplamente conhecido no meio técnico e fartamente documentado $^{2}$, o método não é aqui detalhadamente descrito. Este artigo se concentra, portanto, na determinação dos parâmetros de cálculo e na experiência multidisciplinar realizada pela equipe.

\subsection{Caracterização da Bacia Hidrográfica - metodologia do trabalho}

Para a caracterização física da bacia hidrográfica e obtenção dos parâmetros topológicos do SCS, foram usadas técnicas de geoprocessamento desenvolvidas em 11 etapas, conforme segue.

\section{Georreferenciamento e retificação de cartas escaneadas}

Essa etapa consistiu no georreferenciamento de recortes de cartas planialtimétricas, escala 1:10.000, da Emplasa, que foram previamente escaneadas. As coordenadas das cartas escaneadas foram referenciadas ao Sistema de Projeção UTM, com unidades em metros e datum horizontal Córrego Alegre.

Como pontos de controle no georreferenciamento, foram utilizadas as intersecções da malha de coordenadas UTM presentes em cada um dos recortes, atentando-se para a identificação de, no mínimo, quatro pontos por arquivo/recorte, buscando também minimizar o erro residual do processo de transformação ("RMS - Root Mean Square”, ou Erro Médio Quadrático).

Em seguida, os recortes georreferenciados foram juntados em um único arquivo para compor uma base contínua da área de estudo, permitindo a delimitação das sub-bacias 
e a vetorização de rios, curvas de nível e pontos cotados.

\section{Delimitação das sub-bacias}

A delimitação das sub-bacias foi feita sobre o mosaico gerado na etapa anterior, levando em consideração as características do relevo, representadas nas curvas de nível e nos pontos cotados, e da rede hidrográfica também representada nas cartas da Emplasa. Como resultado, foi gerado um arquivo vetorial com as sub-bacias delimitadas, devidamente codificadas e com as respectivas áreas calculadas pelo SIG (Sistema de Informações Geográficas).

\section{Vetorização dos rios, curvas de nível e pontos cotados}

Para a realização das análises necessárias ao presente estudo em ambiente SIG, foi necessária a conversão das informações matriciais presentes nas cartas da Emplasa (estrutura "raster") para a estrutura vetorial, processo conhecido como vetorização. Assim, a vetorização resultou em três planos de informação ("layers"): rios (representação linear), curvas de nível (representação linear) e pontos cotados (representação pontual). Em seguida, foram inseridos os valores de altitude em cada curva de nível e ponto cotado.

\section{Identificação, obtenção e processamento de imagem de satélite}

Para o estudo do uso atual do solo, foram pesquisadas fontes ostensivas e gratuitas para a obtenção de imagens de sensores de alta resolução como base. A única fonte que atendeu a esses requisitos foi o Google Earth, a partir do qual foi extraído um recorte da imagem que cobre a área da bacia. Essa imagem foi então georreferenciada com base nas cartas da Emplasa.

Note-se que, para as finalidades do estudo e, tendo em vista as características da imagem obtida, esse procedimento mostrou-se suficiente, não sendo realizados outros processamentos para a eliminação ou diminuição de distorções das imagens e para a garantia de alta acuracidade posicional como, por exemplo, ortorretificação.

\section{Classificação da imagem}

A imagem georreferenciada foi classificada conforme as seguintes categorias de uso do solo: 
- Campo;

- Corte ou aterro;

- Estrada de terra;

- Mata ou floresta;

- Solo exposto;

- Superfície impermeável;

- Outros (tipologias não enquadradas nas classes anteriores).

Uma vez definidos os polígonos correspondentes a cada classe de uso, procedeu-se o cálculo das respectivas áreas.

\section{Conversão do arquivo da planta de zoneamento}

Essa etapa consistiu na conversão do "layer" de zoneamento para ambiente SIG, a partir de planta da prefeitura de Santana de Parnaíba no formato dwg (AutoCAD). Os polígonos resultantes do processo de conversão também tiveram suas áreas calculadas pelo SIG.

\section{Geração de Modelo Digital do Terreno (MDT)}

Essa etapa envolveu a geração de um modelo de superfície para representar as elevações do terreno (TIN - Triangulated Irregular Network), visando subsidiar a realização dos demais estudos do presente trabalho (determinação das declividades, perfis, representação 3D, identificação de topos de morros, entre outros).

Para a modelagem da superfície em questão, as curvas de nível e os pontos cotados foram utilizados como massa de pontos, e os rios como linhas de quebra ("breaklines"). Uma vez interpolado o modelo de superfície (malha irregular), o mesmo foi convertido para uma malha regular (raster).

\section{Delimitação das Áreas de Preservação Permanente (APP)}

Tendo em vista a legislação vigente (Código Florestal), foram delimitadas, sobre a base vetorial gerada para o trabalho, as seguintes Áreas de Preservação Permanente: 
- $\quad$ Cursos d'água (buffer/área de isolamento de 30m ao longo dos córregos da bacia);

- $\quad$ Topos de morros/cumeadas (terça parte superior a partir de sua base);

- $\quad$ Nascentes (buffer/área de influência de 50m a partir das nascentes);

- $\quad$ Áreas com declividade superior a 45․

\section{Geração dos perfis dos talvegues da bacia}

A partir dos cursos d'água, foram definidas, nos arquivos vetoriais, as linhas representando cada um dos talvegues das sub-bacias. Em seguida, essas linhas foram cruzadas com as elevações, resultando em perfis de distância x elevação/cota para cada sub-bacia.

\section{Cruzamentos espaciais}

Uma vez gerados todos os dados vetoriais necessários ao estudo, foram realizados os seguintes cruzamentos espaciais:

- $\quad$ Classes de uso do solo e sub-bacias;

- $\quad$ Classes de uso do solo, sub-bacias e APPs;

- $\quad$ Zoneamento e sub-bacias.

Os resultados dos cruzamentos e as respectivas áreas calculadas foram compilados em tabelas.

\section{Resultado: Geração de mapas temáticos}

Os principais mapas gerados são apresentados nas figuras 4 a 9 a seguir. A geração destas bases de estudo e discussão realizada na equipe, e pela equipe técnica com o empreendedor e organismos licenciadores resultou muito importante e produtiva, embasando a estratégia geral do projeto e identificando a situação do trecho analisado para intervenção proposta, num contexto mais amplo. Desta forma o master-plan, desenvolvido na escala local, inserese na metodologia conhecida no campo urbanístico como da "interação escalar", absorvendo importantes informações advindas dos estudos e diagnósticos gerais. 


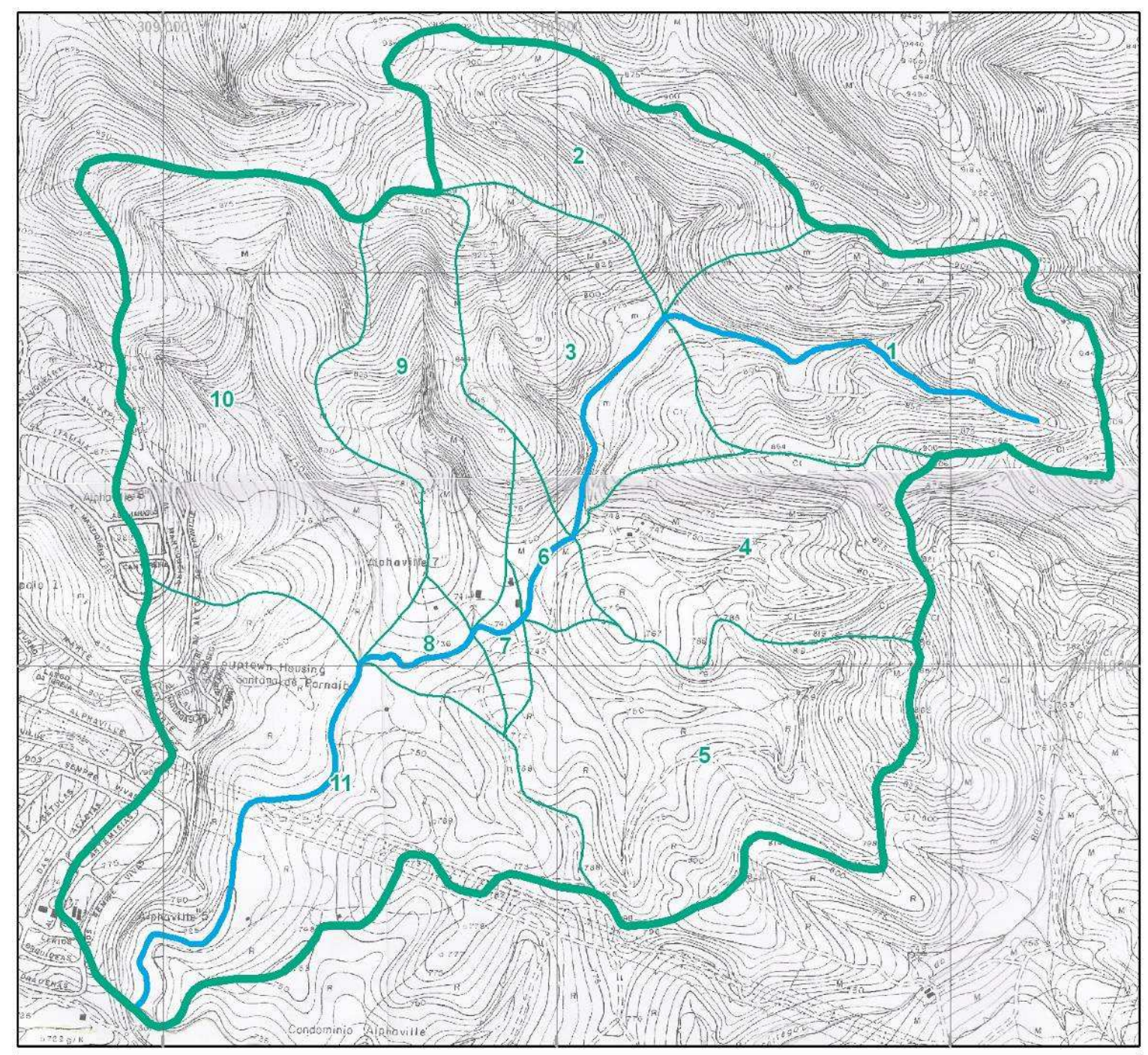

Fonte: Emplasa.

Bacia do Córrego Barreiro

Sub-bacias do Córrego Barreiro

Córrego do Barreiro

\section{FIGURA 4 - BACIA HIDROGRÁFICA DO CÓRREGO DO BARREIRO}

Para o cálculo dos hidrogramas de projeto a bacia foi subdividida em 11 sub-bacias 

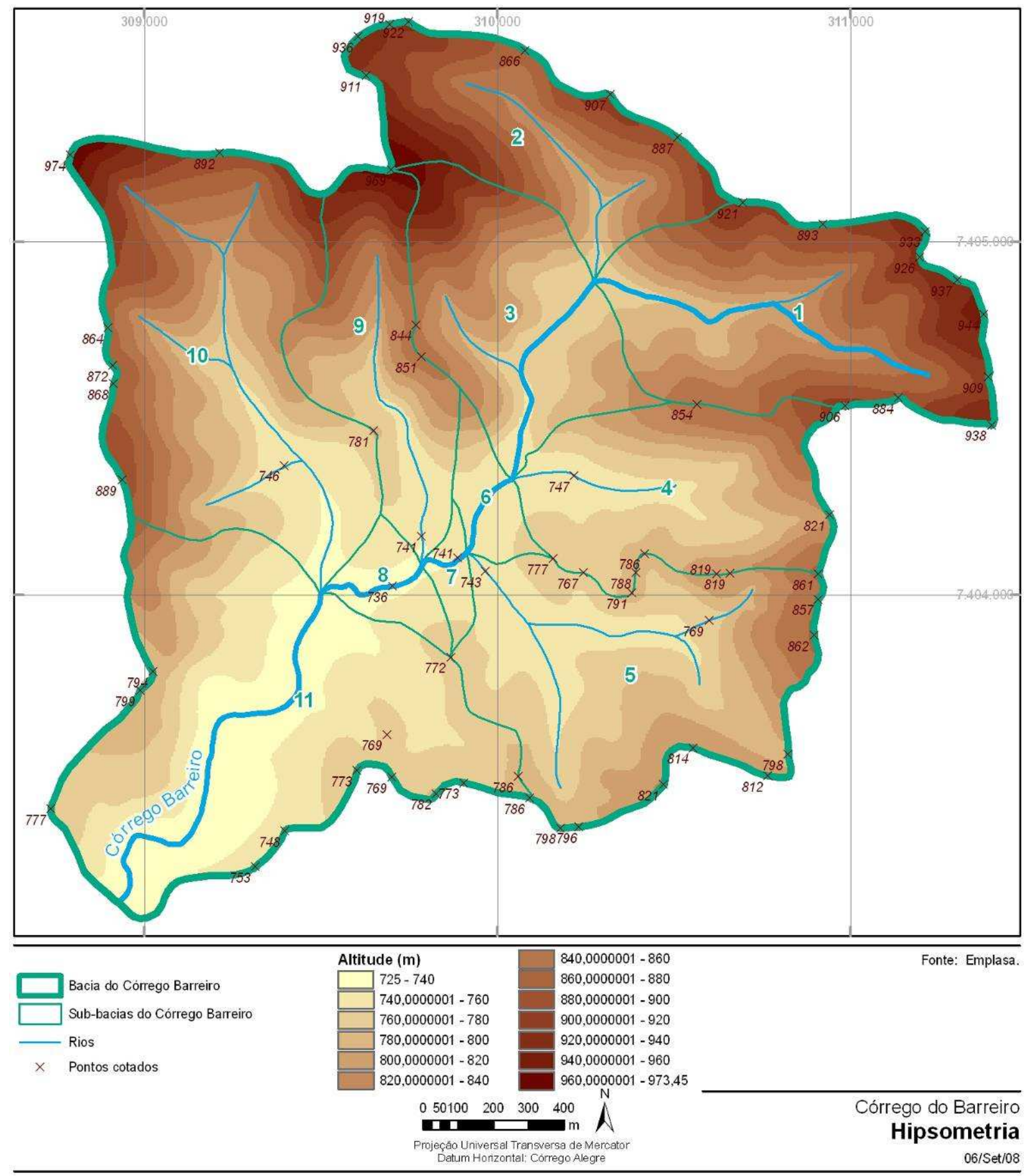

FIGURA 5 - HIPSOMETRIA DA BACIA DO CÓRREGO DO BARREIRO

Os perfis dos talvegues utilizados para o cálculo dos tempos de translação foram construídos a partir da carta hipsométrica 


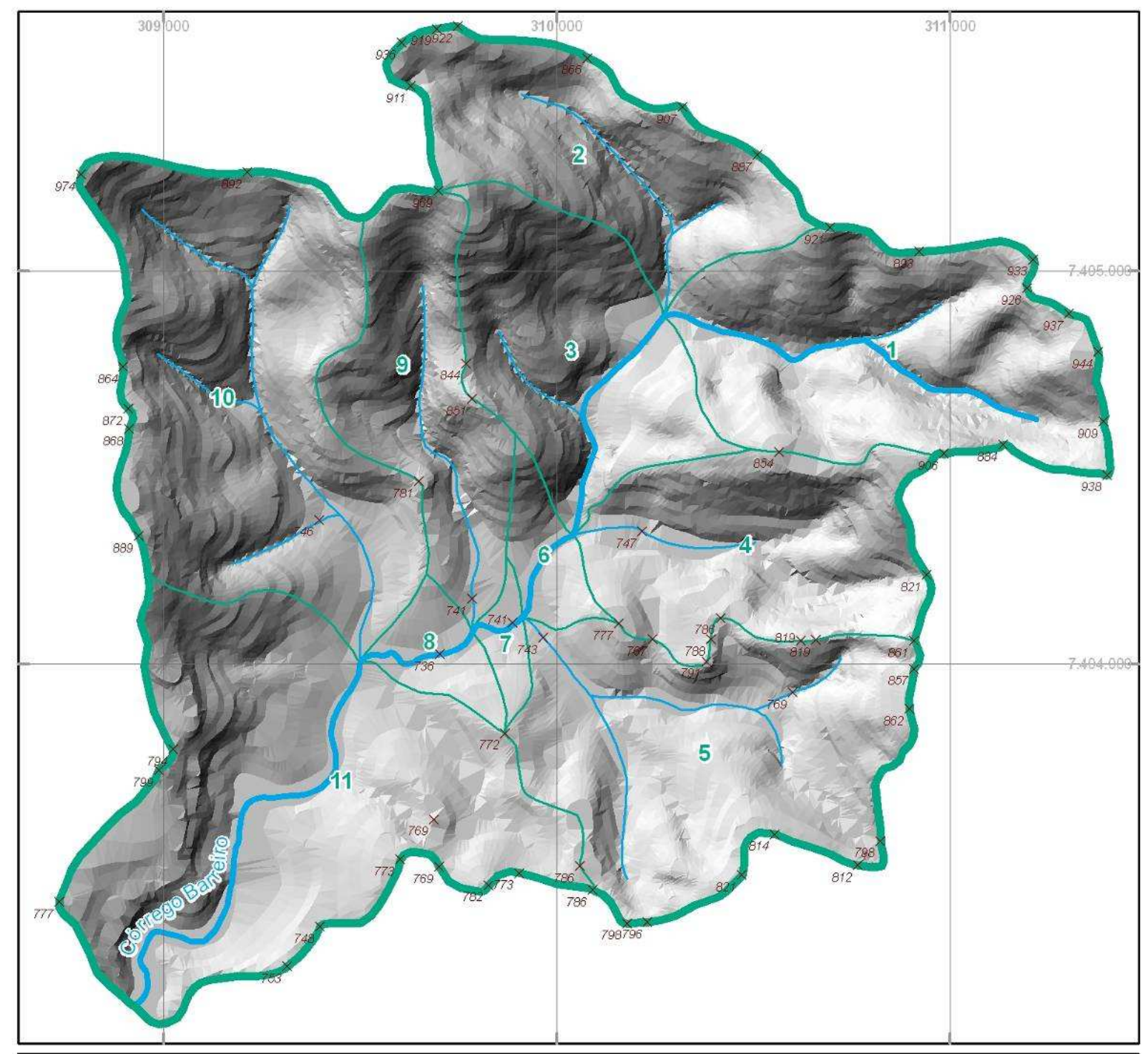

Fonte: Emplasa. Bacia do Córrego Barreiro Sub-bacias do Córrego Barreiro Rios

$\times$ Pontos cotados

FIGURA 6 - REPRESENTAÇÃO DO RELEVO DA BACIA DO CÓRREGO DO BARREIRO

O relevo foi gerado a partir da digitalização das cartas planialtimétricas escala 1:10.000 da EMPLASA 


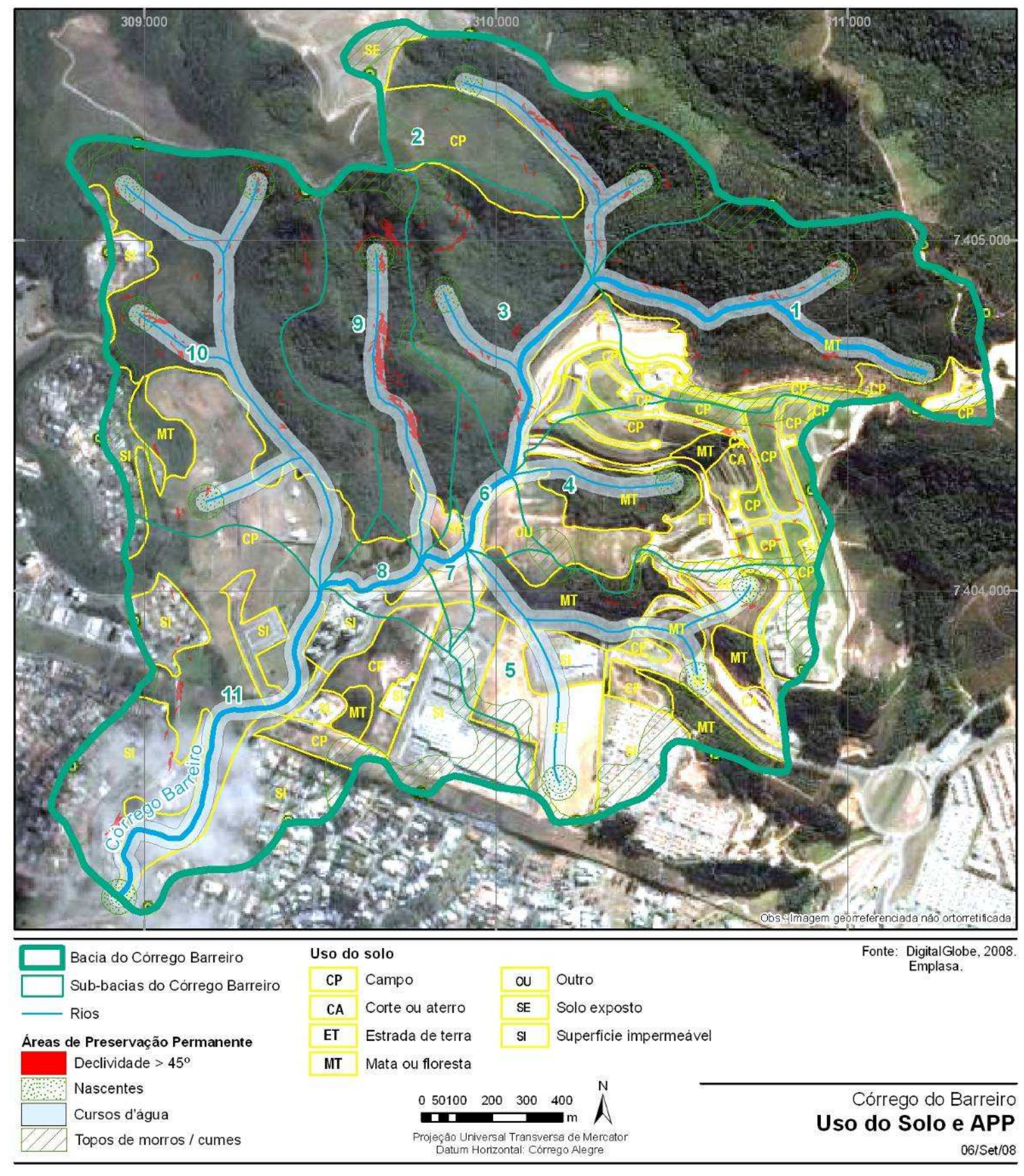

FIGURA 7 - USO ATUAL DO SOLO DA BACIA DO CÓRREGO DO BARREIRO

O mapeamento do uso do solo foi feito por classificação supervisionada de imagem de satélite 


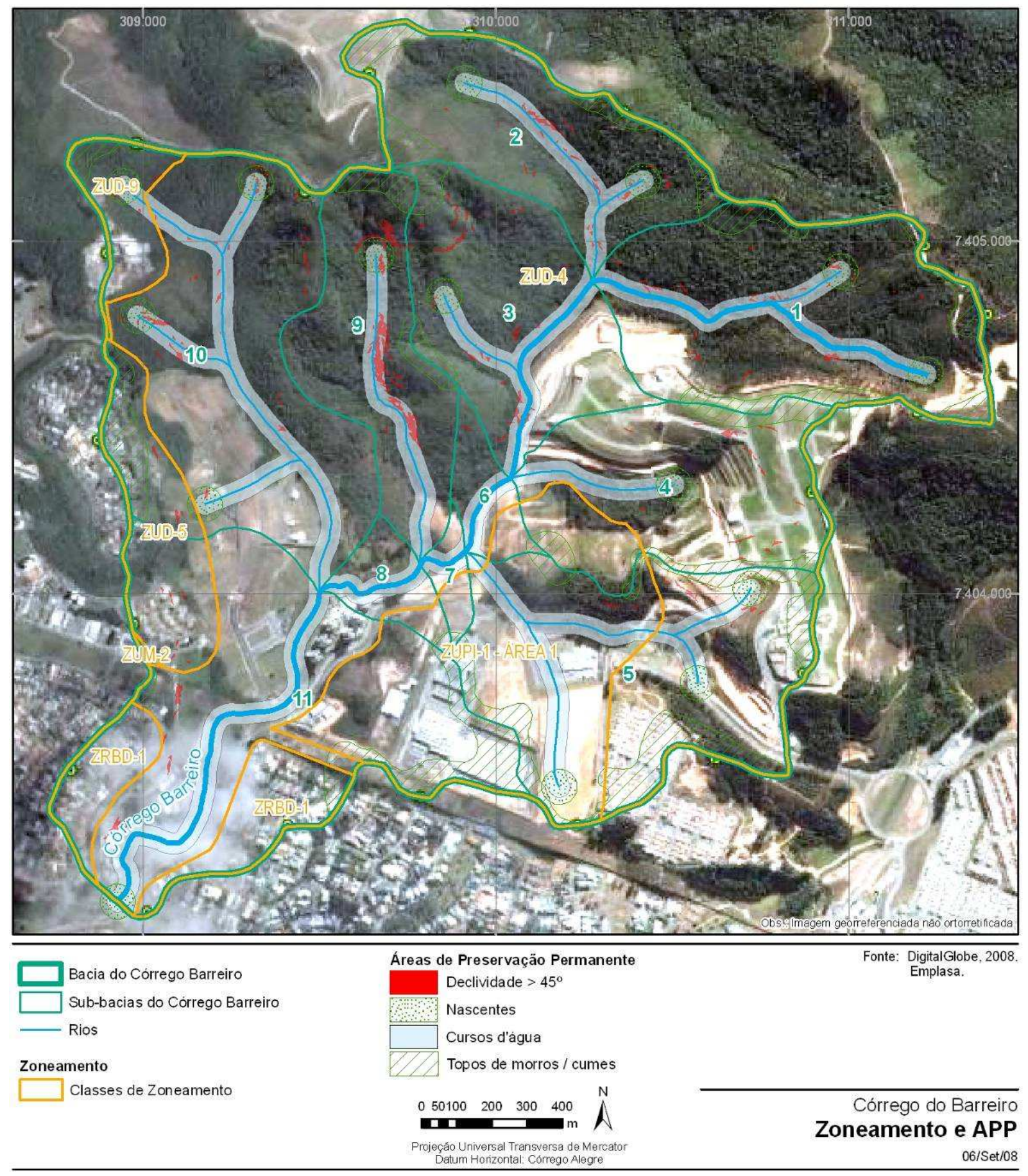

FIGURA 8 - MAPEAMENTO DAS ÁREAS DE PRESERVAÇÃO PERMANENTE E ZONEAMENTO MUNICIPAL

O mapeamento mostra que a ocupação atual já não segue a legislação. 


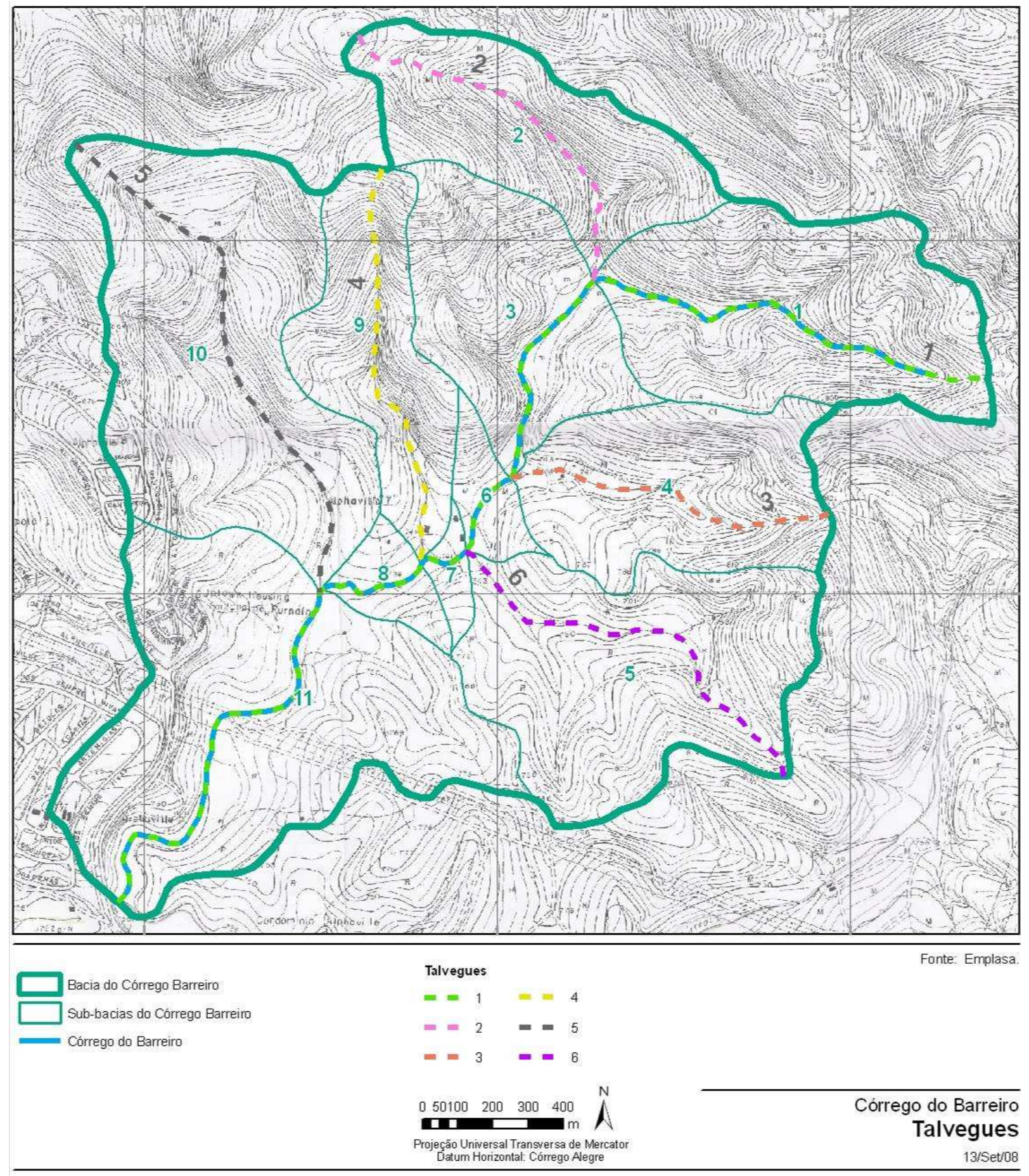

FIGURA 9 - TALVEGUES

Os talvegues, cujos perfis foram traçados são indicados nesta ilustração 


\section{a. Declividades dos Talvegues}

Para o cálculo dos tempos de concentração foram determinadas as declividades médias do talvegue principal e dos afluentes a partir das cotas e curvas de níveis vetorizadas das cartas EMPLASA, como mostrado na figura 9. Os resultados foram apresentados em série de gráficos, conforme o gráfico a seguir.

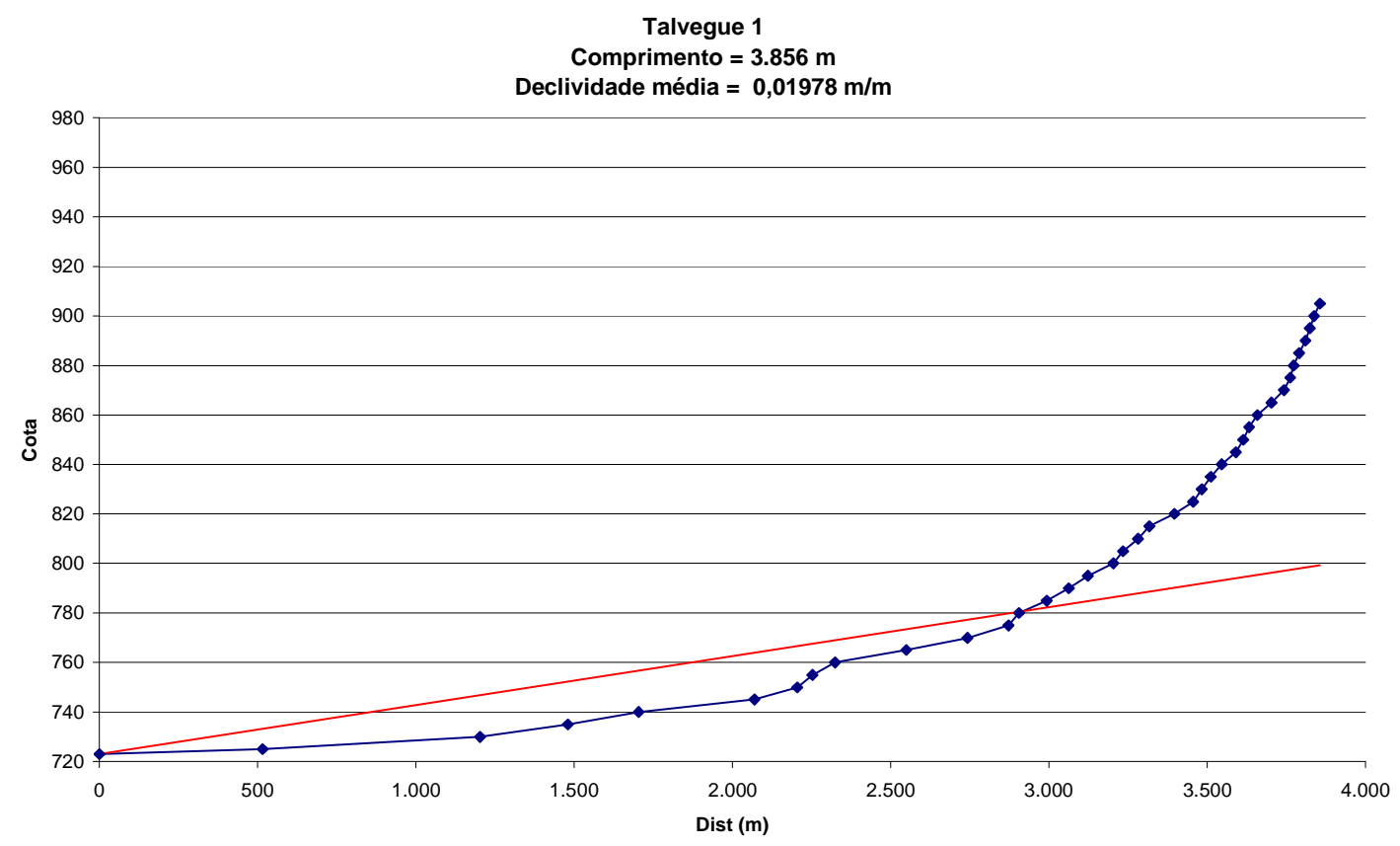

\section{Figura 10}

\section{b. Uso do Solo}

O estudo do uso do solo na bacia do córrego do Barreiro foi desenvolvido para a determinação dos parâmetros $C N$ (Curve Number) do SCS para cada sub-bacia, conforme discretização indicada na Figura 2. Para este estudo foi considerado o zoneamento municipal em vigor, o uso do solo atual, as diretrizes do Plano de Macrodrenagem da Bacia do Alto Tietê (PDMAT) e do Plano da Bacia Hidrográfica da Bacia do Alto Tietê (PAT), estas duas últimas fundamentais para a concessão da outorga das obras propostas.

Verificou-se que há diversas áreas de preservação a montante e que a área de estudo caracteriza-se também como região de amortecimento de eventuais cheias do curso d'água. Os níveis de assoreamento da Lagoa do BACURI, situada a juzante da área, na foz, são preocupantes. 


\section{CONCLUSÕES E PROPOSTAS}

Os resultados obtidos com a utilização do software CLiv para a determinação das linhas de água e das manchas de inundação mostraram que as linhas de água no trecho da UNIP são compatíveis com a urbanização do local e com os níveis das passarelas existente e projetada, tanto para a situação atual como para a situação futura, considerando-se as intervenções propostas.

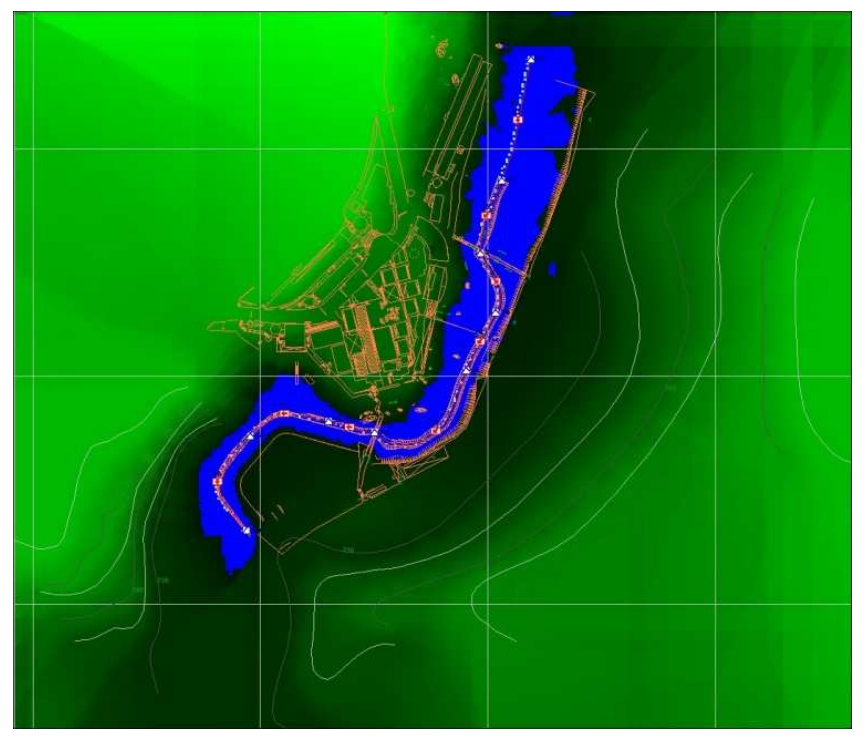

FIGURA 11 - um dos resultados da modelagem realizada a partir do desenho hidro- paisagístico: $(\mathrm{TR}=100$ ANOS $)$

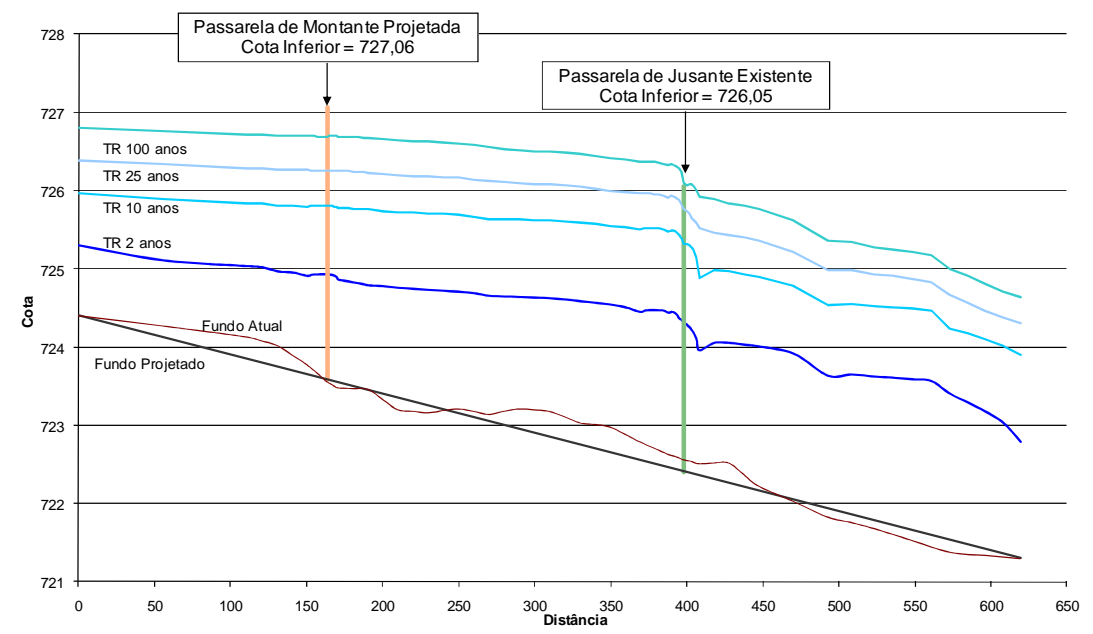

FIGURA 12 - Hidrograma do projeto no trecho 


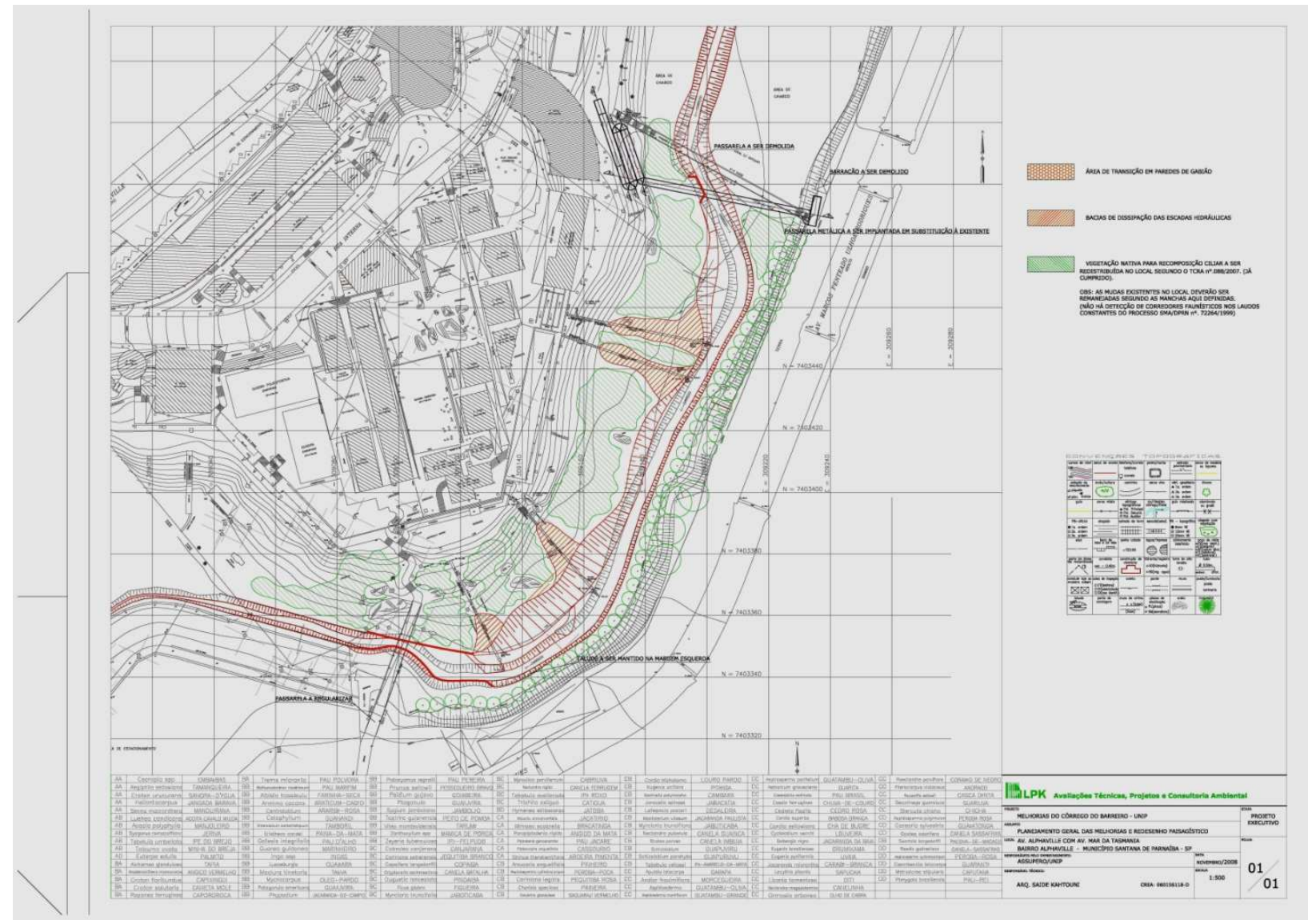

Figura 13 - Situação geral proposta

A equipe constatou que o trecho do córrego situado à juzante, sofre os reflexos da urbanização e obras realizadas a montante, entre eles o assoreamento e o despejo de alguns esgotos, ainda de pequeno impacto.

A partir dos estudos hidrológicos realizados obtivemos a confirmação da cota indicada para a implantação da passarela nova, em substituição ao passadiço em péssimas condições que lá se encontra e obtivemos a outorga pelo DAEE. Em observação às diretrizes de recomposição vegetal indicadas pelo DPRN e pela assessoria de engenharia florestal anteriormente contratada pelo empreendedor traçou-se o plano de melhoramentos acima e a série de desenhos do projeto hidráulico foi produzida, unificando o partido paisagístico ao redesenho do curso d'água, o que resultou, posteriormente, num projeto executivo de intervenção sobre o trecho do córrego e nos projetos da passarela nova a ser construída em breve pela universidade, bem como o conjunto de melhoramentos previstos. Figura 14 - passarela a demolir com área de amortecimento à direita. 


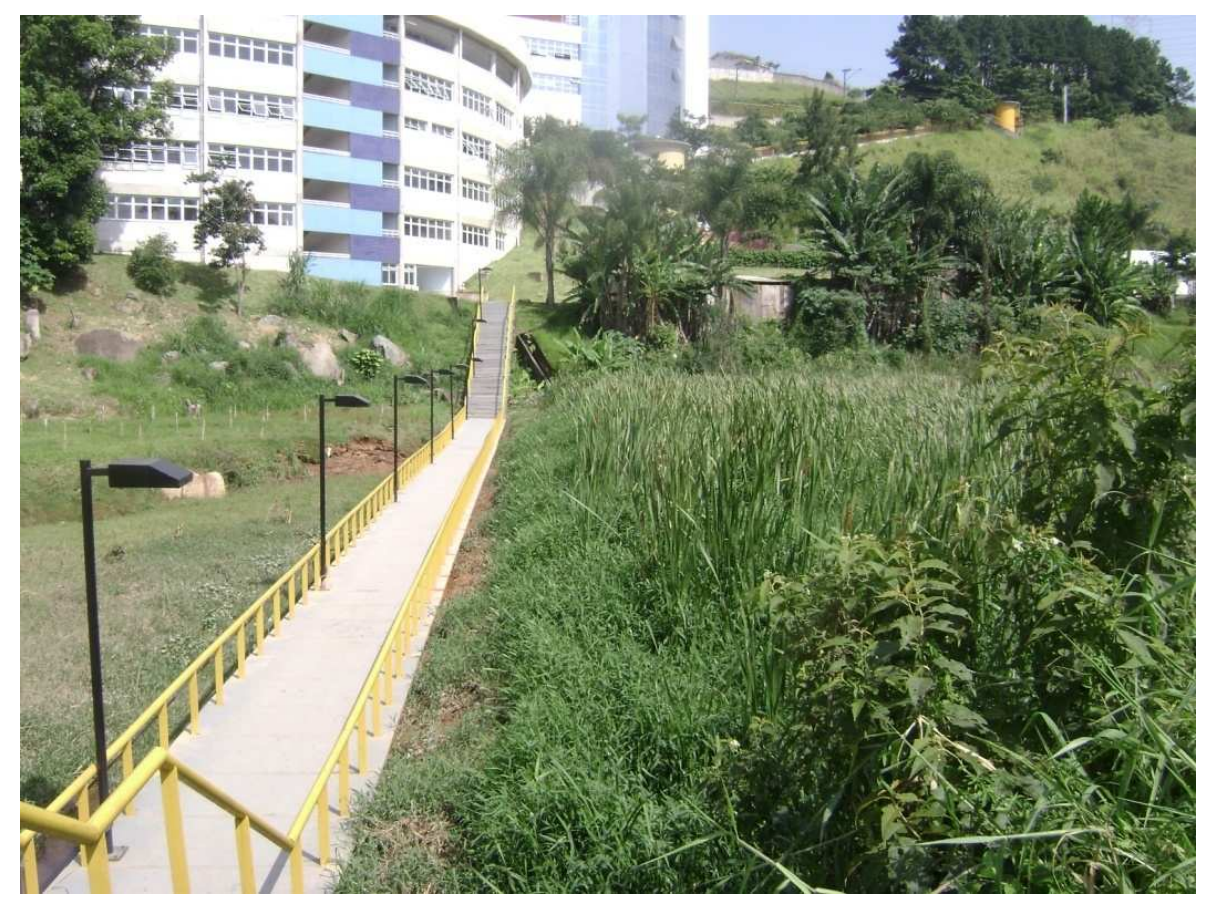

FIGURA 14 - vista geral da área de amortecimento de montante

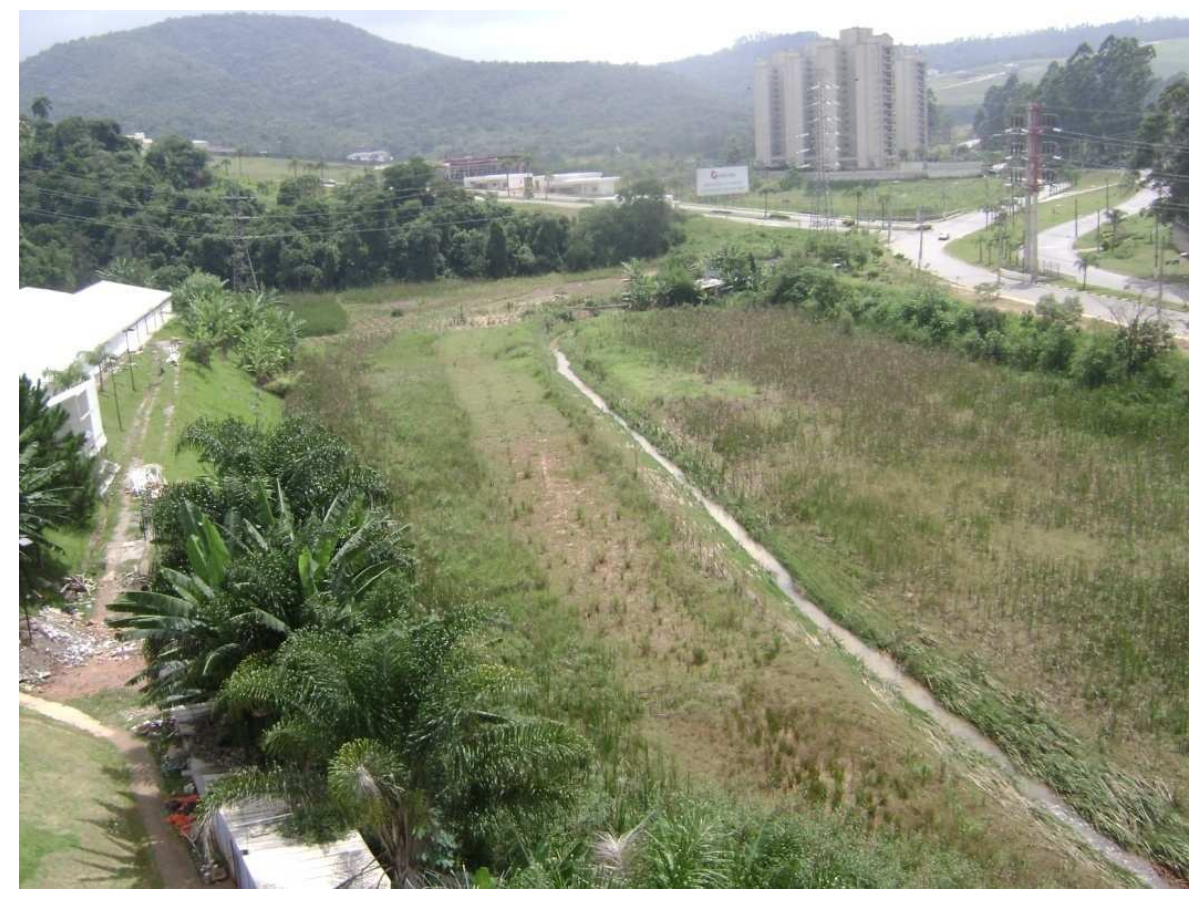

FIGURA 15 - Vista da área de intervenção como está hoje. 


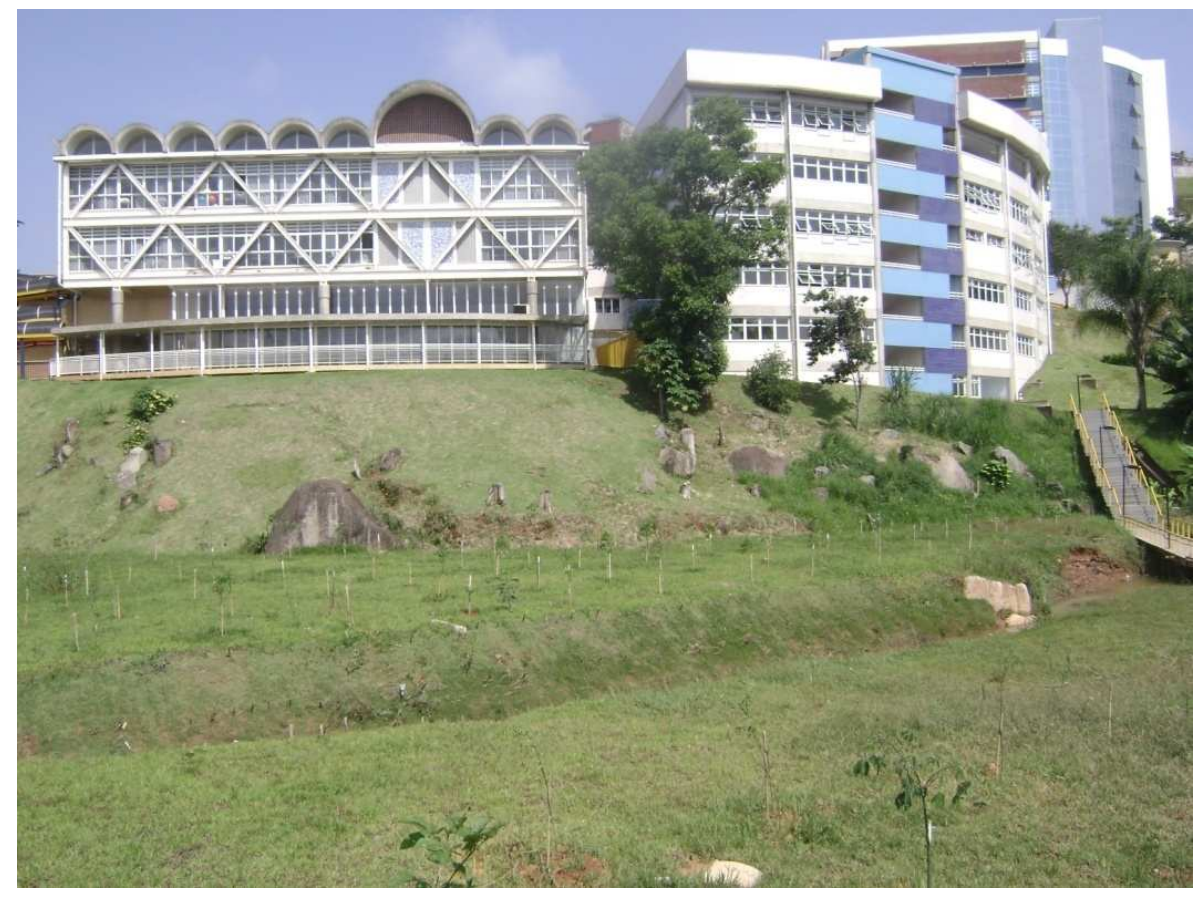

FIGURA 16 - Vista da área de intervenção como está hoje.

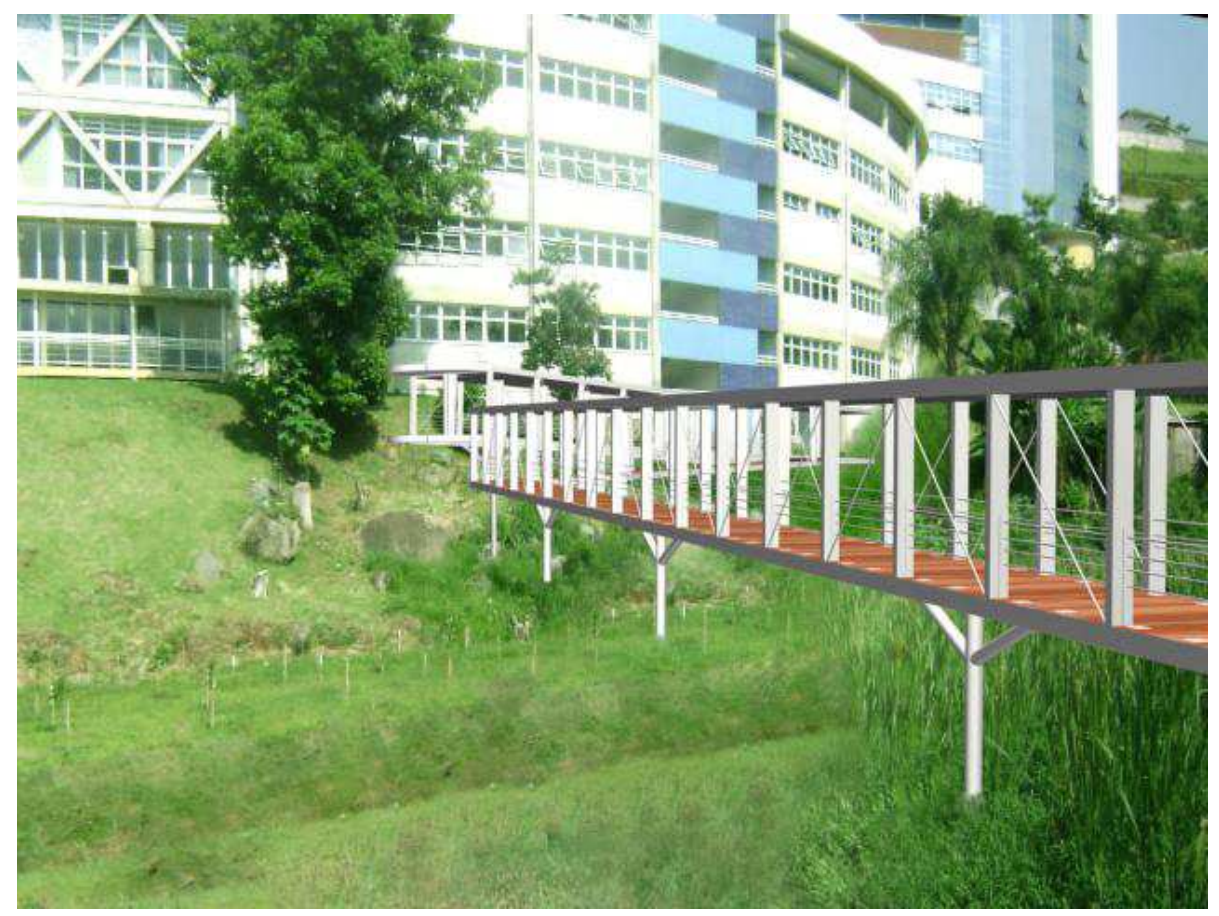

FIGURA 17 - Simulação da implantação passarela nova. 


\section{NOTAS}

${ }^{1}$ Região, sub-região e unidade hidrográfica é a nomenclatura adotada para definir os diferentes níveis de bacias hidrográficas. A bacia do Alto Tietê é subdividida em bacias menores (sub-regiões) que, por sua vez são subdivididas em bacias menores ainda (unidades hidrográficas).

${ }^{2}$ Ver, por exemplo:Diretrizes de Projeto de Hidráulica e Drenagem Urbana - Volume 4, Prefeitura do Município de São Paulo, 1999. CAbc, Software para Simulações Hidrológicas de Bacias Complexas, Manual do Usuário, FCTH, 2005.

\section{AGRADECIMENTOS}

Equipe de análise do DAEE, pelas contribuições e questionamentos.

\section{Equipe técnica multidisciplinar complementar:}

Geográfo Clayton Bitencourt

Engenheiro e geotécnico Marcos Lima Verde Guimarães

Engenheiro Yopanan Conrado Rebelo / assessorial estrutural

Engenheiro José Rodolfo Scarati Martins/ consultoria na modelagem hidráulica

\section{BIBLIOGRAFIA}

DEL RIZZO, L. Mitigazione del rischio idraulico e attività ambientale: le prospettive offerte nel Veneto dal Piano Direttore ad una nuova cultura del território. Consorzio di bonifica Dese Sile. Apresentação realizada à missão brasileira da Cooperação Internacional Brasil-Itália em Saneamento Ambiental. Veneza, Itália, julho de 2007.

FUNDAÇÃO CENTRO TECNOLÓGICO DE HIDRÁULICA - FCTH. CLiv Software para simulação de escoamentos em condutos livres - Manual do usuário. São Paulo, 2006. FUNDAÇÃO CENTRO TECNOLÓGICO DE HIDRÁULICA - FCTH. CAbc Software para simulação hidrológica de bacias complexas - Manual do usuário. São Paulo, 2005. FUSP - FUNDAÇÃO DE APOIO À UNIVERSIDADE DE SÃO PAULO. Plano da Bacia Hidrográfica do Alto Tietê - Diagnóstico Analítico da Bacia. São Paulo, 2007.

KAHTOUNI, S. Cidade das águas. Rima, São Carlos, 2004. 
PREFEITURA DO MUNICÍPIO DE SÃO PAULO. Diretrizes de Projeto de Hidráulica e Drenagem Urbana. Manual técnico. São Paulo, 1999.

WHITAKER, D.; ELKIN, D.; PEARSON, R.; MADER, S.; FAHA, M. Integrating Stormwater Management and Wetlands Mitigation in the "Front Yard" of the Intel Ronler Acres Campus in Hillsboro, Oregon. Ninth International Conference on Urban Drainage, Portland, Oregon, 2002. 